\title{
The Role of Metals in the Reaction Catalyzed by Metal-Ion-Independent Bacillary RNase
}

\author{
Yulia Sokurenko, ${ }^{1}$ Vera Ulyanova, ${ }^{1}$ Pavel Zelenikhin, ${ }^{1}$ Alexey Kolpakov, ${ }^{1}$ \\ Dmitriy Blokhin, ${ }^{2}$ Dieter Müller, ${ }^{3}$ Vladimir Klochkov, ${ }^{2}$ and Olga Ilinskaya ${ }^{1}$ \\ ${ }^{1}$ Institute of Fundamental Medicine and Biology, Kazan Federal University, Kremlevskaya Str. 18, Kazan 420008, Russia \\ ${ }^{2}$ Institute of Physics, Kazan Federal University, Kremlevskaya Str. 16a, Kazan 420008, Russia \\ ${ }^{3}$ Institute for Anatomy and Cell Biology, Justus Liebig University Giessen, Aulweg 123, 35385 Giessen, Germany \\ Correspondence should be addressed to Yulia Sokurenko; sokurenko.yulia@gmail.com
}

Received 25 August 2016; Revised 27 October 2016; Accepted 2 November 2016

Academic Editor: Spyros P. Perlepes

Copyright (C) 2016 Yulia Sokurenko et al. This is an open access article distributed under the Creative Commons Attribution License, which permits unrestricted use, distribution, and reproduction in any medium, provided the original work is properly cited.

\begin{abstract}
Extracellular enzymes of intestinal microbiota are the key agents that affect functional activity of the body as they directly interact with epithelial and immune cells. Several species of the Bacillus genus, like Bacillus pumilus, a common producer of extracellular RNase binase, can populate the intestinal microbiome as a colonizing organism. Without involving metal ions as cofactors, binase depolymerizes RNA by cleaving the $3^{\prime}, 5^{\prime}$-phosphodiester bond and generates $2^{\prime}, 3^{\prime}$-cyclic guanosine phosphates in the first stage of a catalytic reaction. Maintained in the reaction mixture for more than one hour, such messengers can affect the human intestinal microflora and the human body. In the present study, we found that the rate of $2^{\prime}, 3^{\prime}$-cGMP was growing in the presence of transition metals that stabilized the RNA structure. At the same time, transition metal ions only marginally reduced the amount of $2^{\prime}, 3^{\prime}$-cGMP, blocking binase recognition sites of guanine at N7 of nucleophilic purine bases.
\end{abstract}

\section{Introduction}

The $\mathrm{T} 1$ family (EC 3.1.27.3) ribonucleases (RNases) hydrolize RNA and cleave the $3^{\prime}, 5^{\prime}$-phosphodiester bond between guanosine $3^{\prime}$-phosphate and the $5^{\prime}$-OH group of the adjacent nucleotide, forming a $2^{\prime}, 3^{\prime}$-cyclic guanosine phosphate in the first stage of a catalytic reaction. This stage is reversible and is much faster than the second, in which the cyclic intermediate is hydrolyzed to a corresponding $3^{\prime}$-phosphate [1]. Unlike pyrimidine specific RNases that belong to the family of RNase A (EC 3.1.27.5), RNases T1 are guanyl specific; hence, $2^{\prime}, 3^{\prime}$ cyclic guanosine monophosphate $\left(2^{\prime}, 3^{\prime}\right.$-cGMP) can only be cleaved in the second step of catalysis [1]. Many members of genus Bacillus secrete RNases that can perform both stages of the catalytic reaction. Specifically, such species are B. pumilus and $B$. licheniformis that can be isolated from the human gastrointestinal tract, representing resident rather than transient microbiota [2]. The amount of such microorganisms in the gastrointestinal tract significantly exceeds that which can be expected to come from food. Germination of Bacillus spores in the human intestine and transient colonization are part of the life cycle of human related bacilli [3]. Earlier, we have found B. pumilus in the biopsies of human rectal epithelium after preoperative bowel cleansing [4]. Hence, products that are secreted by bacilli can affect the human normal flora and mediate changes in functional activity of the human body. Extracellular bacterial enzymes are key agents in relation to the human body, as they directly interact with epithelial and immune cells [5]. However, it would be erroneous to exclude from this interaction the reaction intermediates, such as $2^{\prime}, 3^{\prime}$-cyclic positional isomers of classic second messengers, namely $3^{\prime}, 5^{\prime}$-cAMP and $3^{\prime}, 5^{\prime}$-cGMP. For instance, it is shown that $2^{\prime}, 3^{\prime}$-cyclic nucleotides are involved in the regulation of mitochondrial permeability $[6,7]$. In addition, $2^{\prime}, 3^{\prime}$-cGMP can promote thymidine incorporation in the DNA of lymphocytes [8] and, similar to $3^{\prime}, 5^{\prime}$-cGMP, can increase severalfold cGMP-dependent ATPase [9]. Although the biological role of $2^{\prime}, 3^{\prime}$-cGMP has not yet been studied in 
detail, it is clear that noncanonical cyclic second messengers, such as $2^{\prime}, 3^{\prime}$-cGMP and $2^{\prime}, 3^{\prime}$-cAMP are produced by animals and plants in response to stress situation that induces RNA degradation $[10,11]$.

It is known that cyclic phosphates can only be hydrolyzed by RNase after all poly- and oligoribonucleotides have been cleaved [12]. Recently, we have established that $2^{\prime}, 3^{\prime}$-cGMP can be maintained in the RNA:binase reaction mixture for more than one hour, which enables binase to manifest its biological effects [13]. Although binase is treated as an enzyme which does not require metal ions for RNA catalysis [14], the objective of this study was to investigate whether divalent metal ions can affect the ability of binase to form $2^{\prime}, 3^{\prime}$-cGMP cyclic intermediate.

\section{Materials and Methods}

2.1. Materials. We used guanyl preferring RNase, binase (molecular weight $12.3 \mathrm{kDa}, 109$ amino acid residues, $\mathrm{pI}=$ 9.5), isolated as a homogeneous protein with catalytic activity, from a culture fluid of a recombinant strain of Escherichia coli BL21, carrying pGEMGX1/ent/Bi plasmid. Binase catalytic activity toward yeast RNA is $14000000 \mathrm{U} / \mathrm{mg}$ at $\mathrm{pH} 8.5$ [15].

Positional isomers of cyclic nucleotides $3^{\prime}, 5^{\prime}-\mathrm{cGMP}$ and $2^{\prime}, 3^{\prime}$-cGMP, tRNA from Torula yeast, and $3^{\prime}, 5^{\prime}$-cGMP were purchased from Sigma-Aldrich (Germany). Ions of transition $\left(\mathrm{Mn}^{2+}, \mathrm{Fe}^{2+}\right.$, and $\left.\mathrm{Co}^{2+}\right)$ and nontransition $\left(\mathrm{Mg}^{2+}, \mathrm{Ca}^{2+}\right.$, and $\mathrm{Zn}^{2+}$ ) elements were compounded in the reaction mixture in the form of high-purity chlorides (analytical grade).

2.2. Determination of Binase Cyclizing Activity. Binase was incubated in a total volume of $200 \mathrm{mcL}$ in $0.5 \mathrm{M}$ Tris- $\mathrm{HCl}$ buffer ( $\mathrm{pH}$ 8.5) with yeast RNA at concentrations, defined for specific experiments, at $37^{\circ} \mathrm{C}$ for $15 \mathrm{~min}$. The catalytic reaction was stopped in cold. Then, $100 \mathrm{mcL}$ EPBS (8.24 MM $\mathrm{Na}_{2} \mathrm{HPO}_{4}, 1.77 \mathrm{MM} \mathrm{NaH} \mathrm{PO}_{4}, 140 \mathrm{MM} \mathrm{NaCl}$, and $\mathrm{pH} 7.4$ ) was added, and the solution was thoroughly mixed and centrifuged for $2 \mathrm{~min}$ at $12000 \times \mathrm{g}$. The supernatant was decanted into a tube containing $60 \mathrm{mcL}$ EPBS and frozen at $-80^{\circ} \mathrm{C}$. The obtained $2^{\prime}, 3^{\prime}$-cGMP product was determined by enzyme immunoassay (ELISA), using antibodies against $3^{\prime}, 5^{\prime}$-cGMP.

2.3. ELISA Measurement of $2^{\prime}, 3^{\prime}-c G M P$ Quantities. We used commercial 96-well plates with immobilized goat anti-rabbit antibodies (secondary antibody), primary rabbit anti-3', $5^{\prime}$ cGMP, and the appropriate reagents in accordance with manufacturer's instructions (IHF, Hamburg, Germany). RNA hydrolysis by guanyl-specific microbial RNases does not lead to the formation of $3^{\prime}, 5^{\prime}$-cGMP [14]. Earlier, we have shown that $2^{\prime}, 3^{\prime}$-cGMP can be detected in cross-reaction with commercial $3^{\prime}, 5^{\prime}$-cGMP antibodies for $2^{\prime}, 3^{\prime}$-cGMP concentrations that exceed $10^{-5} \mathrm{M}(10 \mathrm{nM} / \mathrm{mL}$ and higher $)$ [13]. In total, $50 \mathrm{mcL}$ of test sample, $50 \mathrm{mcL}$ of biotin solution, and $100 \mathrm{mcL}$ of rabbit primary $3^{\prime}, 5^{\prime}$-cGMP antibodies were added to the well and incubated overnight at $4^{\circ} \mathrm{C}$. Then, $200 \mathrm{mcL}$ of freshly prepared solution of streptavidinhorseradish peroxidase conjugate was added to the well, which was incubated for $30 \mathrm{~min}$ at $4^{\circ} \mathrm{C}$. Thereafter, the plate was washed three times with buffer, filled with $250 \mathrm{mcL}$ of $3^{\prime}, 3,5^{\prime}, 5$-tetramethylbenzidine solution, and maintained at $4^{\circ} \mathrm{C}$ for $40 \mathrm{~min}$. Then, $50 \mathrm{mcL}$ of $2 \mathrm{M} \mathrm{H}_{2} \mathrm{SO}_{4}$ was added and the plate was incubated for $5 \mathrm{~min}$ and analyzed on a colorimeter at $450 \mathrm{~nm}$. The colour intensity is inversely proportional to the amount of cyclic nucleotides that bound to antibody. Concentrations of cyclic nucleotides were calculated by using the calibration curve [13].

2.4. NMR Spectroscopy. Binase ${ }^{1} \mathrm{H}$ NMR-spectra in an aqueous solution that contained chlorides of transition $\left(\mathrm{Mn}^{2+}\right)$ and nontransition metals $\left(\mathrm{Mg}^{2+}, \mathrm{Zn}^{2+}\right)$, as well as tRNA that contained $\mathrm{Mn}^{2+}$ in aqueous solution, were recorded on a NMR spectrometer AVANCE III-700 (700 MHz, Bruker, Germany), equipped with a quad cryogenic sensor $\left({ }^{1} \mathrm{H},{ }^{13} \mathrm{C}\right.$, ${ }^{15} \mathrm{~N}$, and ${ }^{31} \mathrm{P}$ ) CryoProbe. ${ }^{1} \mathrm{H}$ NMR recording of tRNA spectra in the aqueous solution with ions of nontransition metals $\left(\mathrm{Mg}^{2+}, \mathrm{Ca}^{2+}\right.$, and $\left.\mathrm{Zn}^{2+}\right)$ was performed by using an NMR spectrometer AVANCE II-500 (500 MHz, Bruker, Germany).

The spectrometers operated in the mode of internal stabilization at the resonance line ${ }^{2} \mathrm{H}$. The ${ }^{1} \mathrm{H}$-NMR-spectra were recorded using $90^{\circ}$ pulses (pulse relaxation delay $2 \mathrm{c}$; spectral width $20.00 \mathrm{ppm}$; the number of accumulations of 100). NMR-spectra were recorded at $298 \mathrm{~K}, \mathrm{pH} 5.5$.

\section{Results}

3.1. Spectral Characteristics of RNase and RNA's Interaction with Divalent Metal Ions. As binase activity is not dependent on any cofactors or metal ions [14], the spectral characteristics of binase were not changed when divalent ions were added to the protein (Figure 1). RNA interaction with $\mathrm{Mn}^{2+}$ led to a broader signal in the NMR spectrum (Figure $2(\mathrm{~d})$ ). Therefore, it can be assumed that site-specific $\mathrm{Mg}^{2+}, \mathrm{Ca}^{2+}$, and $\mathrm{Zn}^{2+}$ RNA interactions are not present in RNA. The relation of the NMR spectral width and the amount of salt in the studied concentrations $(0.5-5 \mathrm{mM})$ was found to be insignificant. Unlike $\mathrm{Mn}^{2+}$, these ions do not have strong paramagnetic properties and, therefore, have no pronounced effect on RNA in the NMR spectrum (Figures 2(a), 2(b), and 2(c)). Speaking of RNA-Mn ${ }^{2+}$ interaction, we could observe a selective and progressive broadening of NMR signal lines in the ${ }^{1} \mathrm{H}$ NMR spectrum of tRNA in the region of $5-8 \mathrm{ppm}$ where the proton signals of nitrogenous bases are located (Figure 2(d)). The NMR signal lines disappeared after we increased the concentration of $\mathrm{MnCl}_{2}$. Due to a significant decrease in the relaxation time for protons in the vicinity of the paramagnetic center, we detected nucleotides that had nonzero dipolescalar interaction with electron spin of metal's nucleus. The recorded shorter relaxation time, as well as similar changes in the NMR-spectra that are associated with the interaction of $\mathrm{Mn}^{2+}$ and $\mathrm{Co}^{2+}$ with histidine residues and peptide bound glutamate can be due to $\mathrm{Mn}^{2+}$ activity [16].

3.2. Change in the Rate of $2^{\prime}, 3^{\prime}-c G M P$ in RNA Catalytic Cleavage by Binase due to Divalent Metal Ion Activity. Using antibodies that are applied to define the rate of the intermediate metabolite $2^{\prime}, 3^{\prime}$-cGMP in the tRNA-binase reaction, 


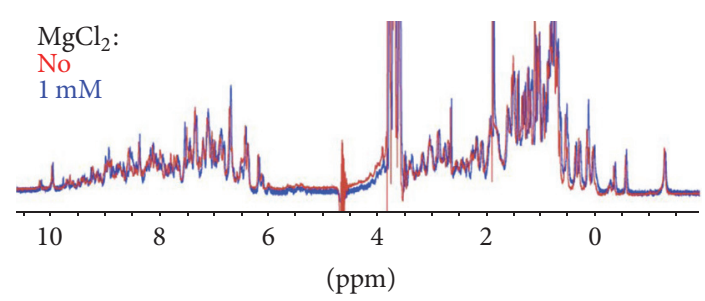

(a)

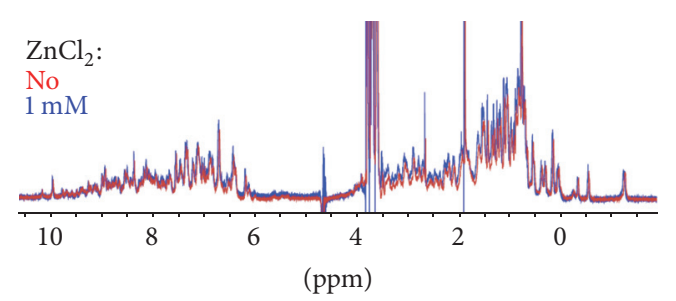

(b)

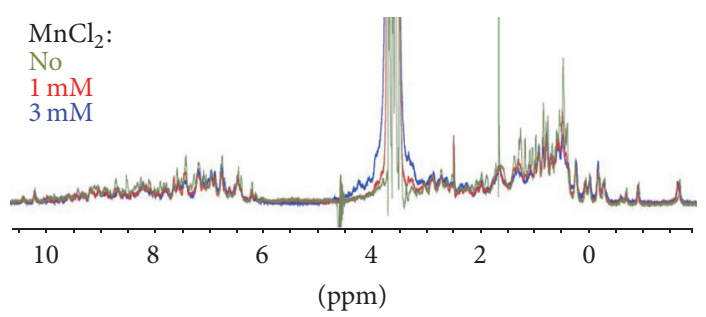

(c)

Figure 1: Regions of ${ }^{1} \mathrm{H}$ NMR titration (700 MHz) for binase with increasing amount of (a) $\mathrm{MgCl}_{2}$ from 0 to $1 \mathrm{mM}$, (b) $\mathrm{ZnCl}$ from 0 to $1 \mathrm{mM}$, and (c) $\mathrm{MnCl}_{2}$ from 0 to $3 \mathrm{mM}$. Binase concentration was $1 \mathrm{mg} / \mathrm{mL}$. NMR-spectra were recorded at $298 \mathrm{~K}, \mathrm{pH} 5.5$.

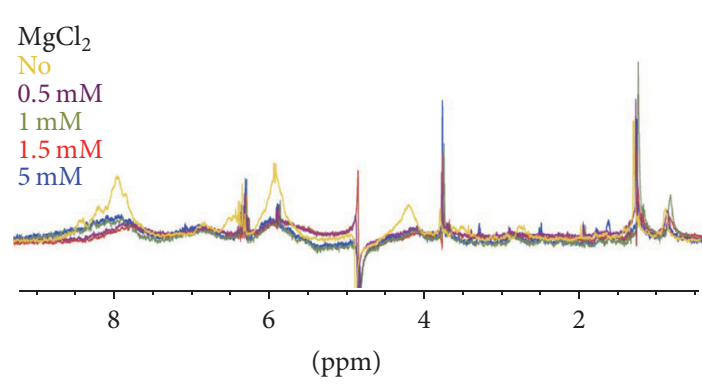

(a)

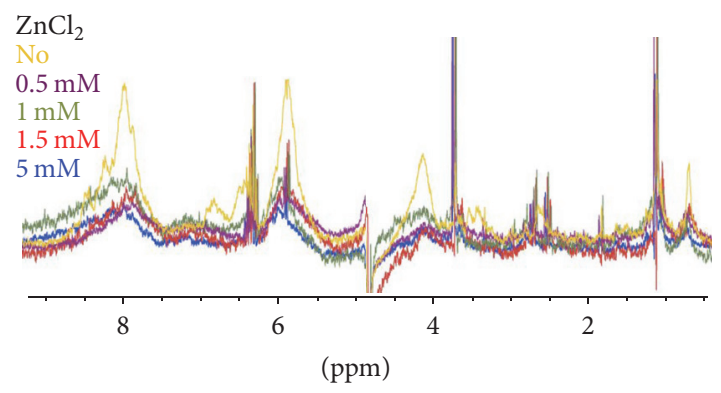

(c)

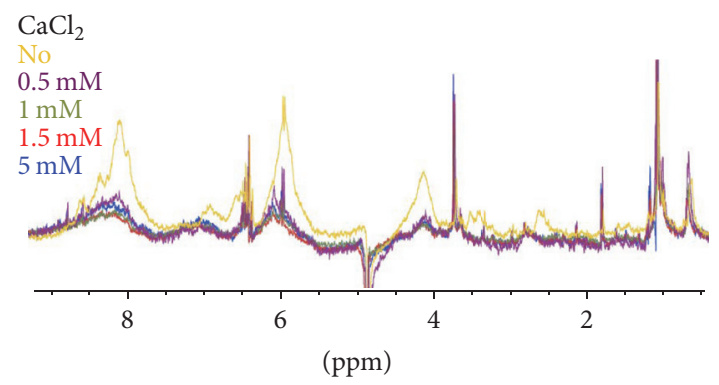

(b)

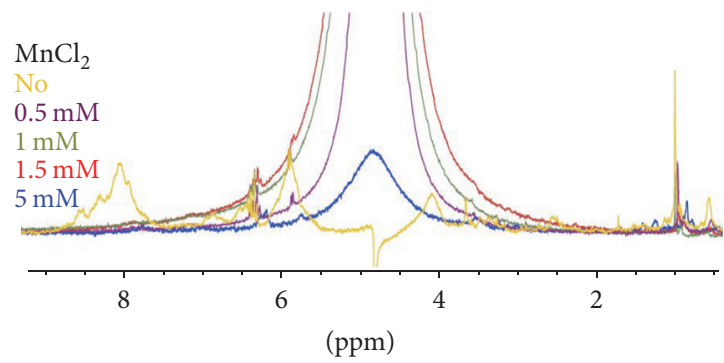

(d)

Figure 2: Regions of ${ }^{1} \mathrm{H}$ NMR titration (500 MHz) for RNA with increasing amount of (a) $\mathrm{MgCl}_{2}$, (b) $\mathrm{CaCl}_{2}$, (c) $\mathrm{ZnCl}_{2}$, and (d) $\mathrm{MnCl}_{2}$ from 0 to $5 \mathrm{mM}$. RNA concentration was $1 \mathrm{mg} / \mathrm{mL}$. NMR-spectra were recorded at $298 \mathrm{~K}$, pH 5.5.

we have shown that the level of the $2^{\prime}, 3^{\prime}$-cGMP product increased by $2-2.5$ times in a reaction mixture containing nontransition metal ions compared to the mixture that had no ions added (Figure $3(\mathrm{a})) . \mathrm{Mn}^{2+}, \mathrm{Co}^{2+}$, and $\mathrm{Fe}^{2+}$ had no stimulating impact on the rate of $2^{\prime}, 3^{\prime}$-cGMP. On the contrary, the rate of $2^{\prime}, 3^{\prime}$-cGMP insignificantly dropped due to higher levels of ion concentration (Figure 3(b)).

\section{Discussion}

It is known that tertiary RNA structure can be stabilized by divalent metal ions at physiological pH [17]. Previously it was thought that since RNA can renature in the presence of both divalent and monovalent ions, divalent ion binding to RNA is due to a common electrostatic interaction of ions 


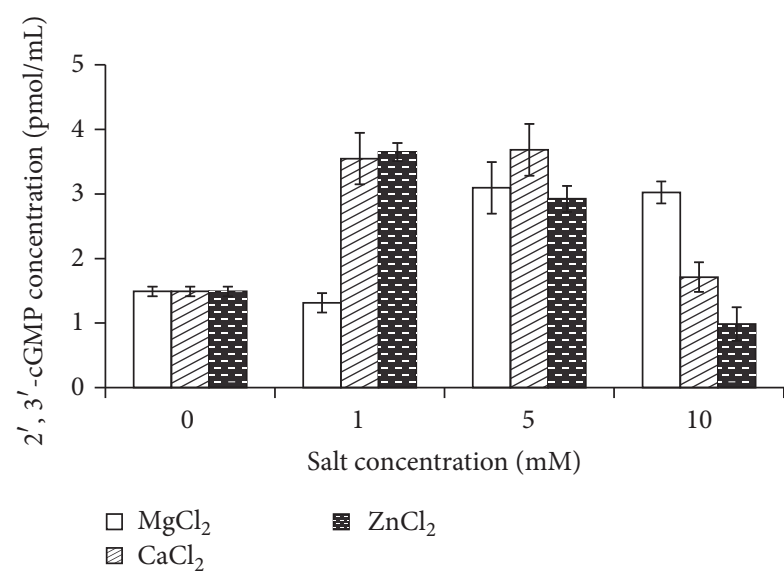

(a)

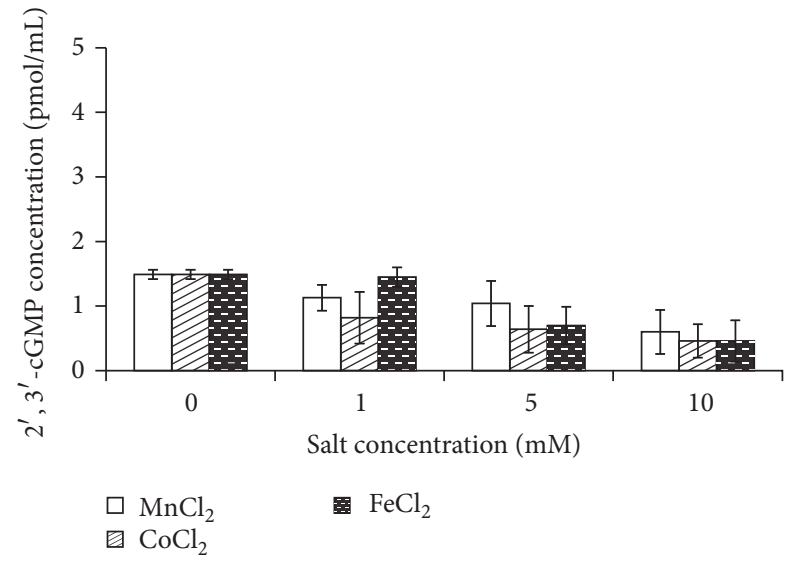

(b)

FIGURE 3: The impact of nontransition (a) and transition (b) metal ions on the rate of $2^{\prime}, 3^{\prime}$-cGMP during catalytic cleavage of RNA by binase.

with phosphates [18]. Later it was shown that the associative behaviour of metal cations towards RNA depends on its structural organization and nucleotide sequence [19]. In addition to formation of complexes with negatively charged deprotonated phosphates, metal cations also interact with some electron donors of oxygen and nitrogen atoms that are part of nitrogenous bases, excluding exocyclic nitrogen atoms [17]. The interaction is due to both stable binding of RNA by fully solvated cations via one or two layers of water molecules and strong relationships of negatively charged functional RNA groups, which are directly coordinated by partially dehydrated cations [20]. Today it is clear that divalent metal ions play a key role in the allosteric regulation of enzymatic activity of RNA [21, 22].

It is difficult to interpret the role of ions, as it is hard to distinguish between the direct catalytic impact of ions and the indirect role of ions in active RNA structure. Recently, it has been found that the transition metals such as $\mathrm{Ni}^{2+}, \mathrm{Co}^{2+}$, and $\mathrm{Mn}^{2+}$ have specific binding sites in RNA, in particular in the riboswitch structure [23]. $\mathrm{Mg}^{2+}, \mathrm{Mn}^{2+}$, and $\mathrm{Zn}^{2+}$ interact with guanosine as a cosubstrate and change the parameters of the catalytic reaction in the first step of splicing [24]. Ions of transition and nontransition metals are not interchangeable in terms of manifested regulatory effects. For instance, riboswitches that are found in the $5^{\prime}$-untranslated region of the Salmonella typhimurium transcription, which is conserved among Gram-negative enteric bacteria, are allosterically activated by $\mathrm{Mn}^{2+}$, rather than by $\mathrm{Ca}^{2+}$ or $\mathrm{Mg}^{2+}$ [25]. For several group I intron ribozymes, folding and catalysis activate the ions of $\mathrm{Mg}^{2+}$, but not $\mathrm{Mn}^{2+}$. It was established that, for intron of $23 \mathrm{~S}$ rRNA gene of the large ribosomal subunit Chlamydomonas reinhardtii, $\mathrm{Mn}^{2+}$ has no inhibitory effect on catalysis but causes misfolding of ribozyme. GMP, a cosubstrate of the group I introns displaces $\mathrm{Mn}^{2+}$ from the binding site of guanosine (GUC) and restores the folding [26].

We have shown that transition and nontransition ions have different impact on the tRNA structure and $2^{\prime}, 3^{\prime}$-cGMP (Figures 2 and 3$)$. tRNA consists of 3-4 strong $(\mathrm{Kd} \approx \mu \mathrm{M})$ and more than 20 weak $\mathrm{Mg}^{2+}$-binding sites [27]. The latter includes the 8-12 turn (Op-U8, Op-A9), D-loop (Op-A20,

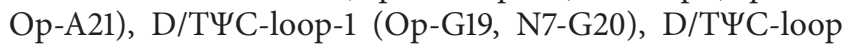
2 (Op-G57, Op-A14), acceptor arm (G3•U70), and the anticodon loop (Op-Y37) [28]. RNA- $\mathrm{Mg}^{2+}$ interaction is primarily mediated by direct binding of oxygen atoms in spatially close phosphate groups and, to a lesser extent, by binding of $2^{\prime}$-hydroxyl groups, N7 atom of purine bases, and ketooxygen atoms ( $\mathrm{U}$ and $\mathrm{G}$ ). RNA- $\mathrm{Mg}^{2+}$ binding motifs are represented by (1) the major groove of mixed $G \cdot U$ pair, followed by $\mathrm{Y} \bullet \mathrm{G}$ pair; (2) shifted G•A pair; (3) magnesium "clamp"; (4) metal ion lightning; (5) E-loop motif; (6) AA platform; and (7) phosphate guanine binding motif [29].

Unlike $\mathrm{Mg}^{2+}, \mathrm{Mn}^{2+}$ ions are only bound in the tRNA molecules with the D/T $\Psi$ C-loop-1 and the acceptor arm [28]. Only one of the seven motifs that are characteristic of $\mathrm{Mg}^{2+}$ binding sites, namely, the shifted G•A pair, is reported for $\mathrm{Mn}^{2+}$ (Figure 4) [29].

Despite having similar radius, charge, and RNA site, $\mathrm{Mg}^{2+}$ and $\mathrm{Mn}^{2+}$ are not identical [30]. $\mathrm{Mg}^{2+}$ and $\mathrm{Mn}^{2+}$ have different orientations within the metal-binding site due to cation preference to a given type of bond in RNA. Thus, the position of $\mathrm{Mg}^{2+}$ being a solid ion strongly depends on the tight coupling of $\mathrm{P}-\mathrm{O}$, while $\mathrm{Mn}^{2+}$ is closer to the N7 position of guanine, wherein the interaction with the oxygen of the previous phosphodiester bond is maintained [31]. Transition metals bind nucleic acid more tightly than $\mathrm{Mg}^{2+}$ or $\mathrm{K}^{+}$, which is largely due to the interaction with nucleophilic nitrogenous bases (N7 purine) [17].

Therefore, the characteristic behaviour of $\mathrm{Mn}^{2+}$ in the NMR spectroscopy of RNA can be explained by its affinity to N7 purines (Figure 2(d)). Guanine binding of $\mathrm{Mn}^{2+}$ ions either limits accessibility for guanyl-specific binase sites in RNA or hinders the recognition of guanine. As a result, we observed no increase in the rate of $2^{\prime}, 3^{\prime}$-cGMP, as a reaction intermediate catalyzed by cyclizing RNases (Figure 3(b)). Based on the obtained evidence on the ability of nontransition metal ions to activate $2^{\prime}, 3^{\prime}$-cGMP, which is not the case of transition metal ions, it can be assumed that the investigated transition metals affect RNA-binase binding sites; the related 


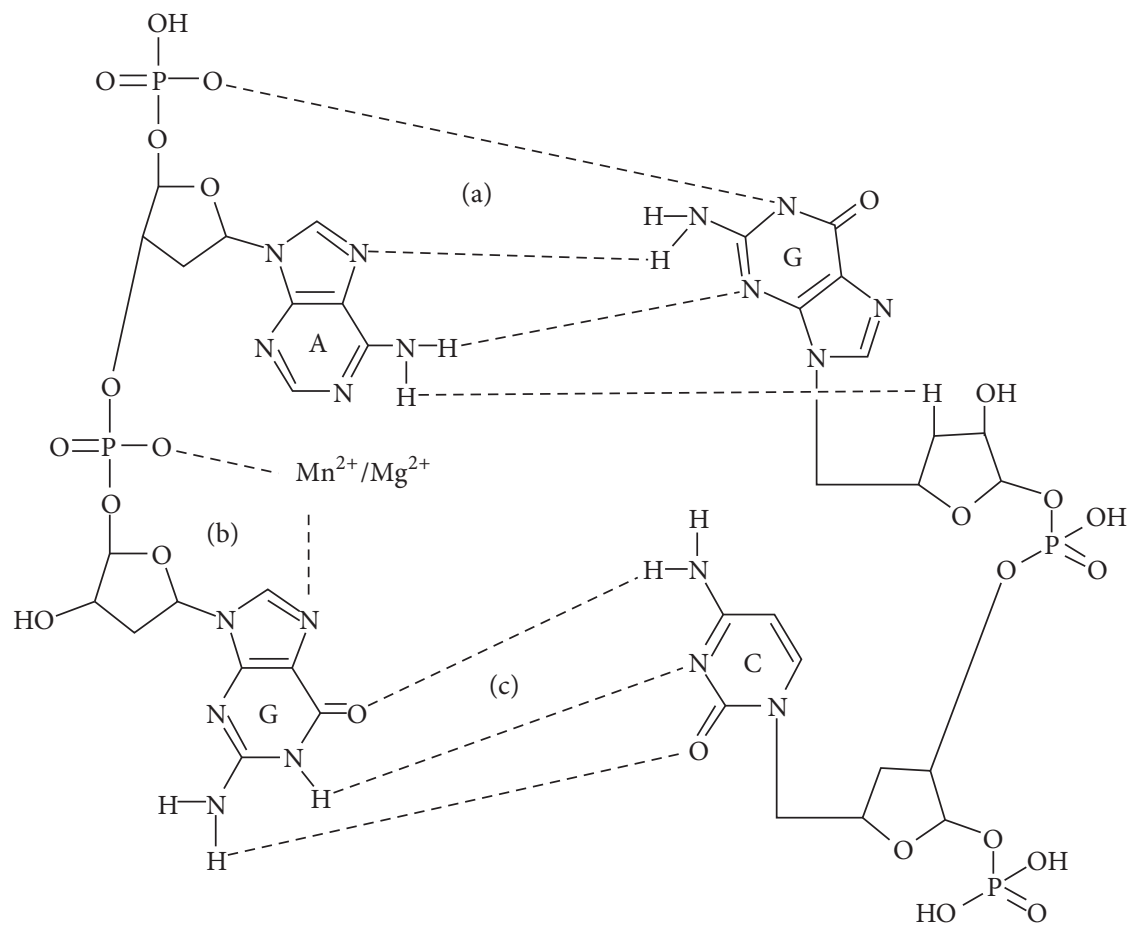

FIGURE 4: Binding site of $\mathrm{Mn}^{2+}$ and $\mathrm{Mg}^{2+}$ ions in RNA. Noncanonical (G•A) (a) and canonical Watson-Crick (G:C) (c) binding of RNA nucleotides. Thermodynamic stability of $\mathrm{G} \bullet \mathrm{A}$ and $\mathrm{G}: \mathrm{C}$ (b) pairs is due to four and three hydrogen bonds, respectively. Hydrated ions of $\mathrm{Mn}^{2+}$ or $\mathrm{Mg}^{2+}$ (water molecules that are involved in coordination of RNA by metal ions are not depicted in the figure) coordinated the N7 level of guanine for the G:C pair and oxygen phosphoric acid residue of the adjacent phosphodiester bond; $\mathrm{Mn}^{2+}$ has a greater affinity to nucleophilic nitrogenous bases, and $\mathrm{Mg}^{2+}$ tends to form a rigid bond of $\mathrm{P}-\mathrm{O}$.

impact is particularly strong in those cases where RNA is stabilized by phosphate groups.

Binase is a promising therapeutic agent with anticancer [32-36] and antivirus effects [37, 38]. Secretion of RNase by bacilli in the intestinal flora is a natural defense mechanism that counters oncogenesis and viral infections. The activation of $2^{\prime}, 3^{\prime}$-cGMP by nontransition metals in the human body can definitely support biological effects of microbial RNases.

\section{Conclusions}

It was shown that the rate of $2^{\prime}, 3^{\prime}$-cGMP, produced by binase during RNA cleavage, was increased in the presence of nontransition metals that stabilized the RNA structure. In the case of transition metal ions the amount of $2^{\prime}, 3^{\prime}$-cGMP was reduced because of blocked guanine in binase recognition sites of RNA. As production of RNase by bacilli in the human body is a natural mechanism, the activation of $2^{\prime}, 3^{\prime}$-cGMP by nontransition metals can enhance biological effects of binase.

\section{Competing Interests}

The authors declare that there is no conflict of interests regarding the publication of this article.

\section{Acknowledgments}

The research was performed within the Russian Government Program of Competitive Growth of Kazan Federal University and supported by the Russian Research Foundation Grant no. 14-14-00522.

\section{References}

[1] H. Yoshida, "The ribonuclease T1 family," Methods in Enzymology, vol. 341, pp. 28-41, 2001.

[2] S. Fakhry, I. Sorrentini, E. Ricca, M. De Felice, and L. Baccigalupi, "Characterization of spore forming Bacilli isolated from the human gastrointestinal tract," Journal of Applied Microbiology, vol. 105, no. 6, pp. 2178-2186, 2008.

[3] H. A. Hong, E. To, S. Fakhry, L. Baccigalupi, E. Ricca, and S. M. Cutting, "Defining the natural habitat of Bacillus sporeformers," Research in Microbiology, vol. 160, no. 6, pp. 375-379, 2009.

[4] N. T. Nguyen, R. R. Vafin, I. V. Rzhanova et al., "Molecular genetic analysis of microorganisms with intraepithelial invasion isolated from patients with colorectal cancer," Molecular Genetics, Microbiology and Virology, vol. 31, no. 1, pp. 15-20, 2016.

[5] B. Sánchez, M. C. Urdaci, and A. Margolles, "Extracellular proteins secreted by probiotic bacteria as mediators of effects 
that promote mucosa-bacteria interactions," Microbiology, vol. 156, no. 11, pp. 3232-3242, 2010.

[6] T. Azarashvili, O. Krestinina, A. Galvita et al., "Ca ${ }^{2+}$-dependent permeability transition regulation in rat brain mitochondria by $2^{\prime}, 3^{\prime}$-cyclic nucleotides and $2^{\prime}, 3^{\prime}$-cyclic nucleotide $3^{\prime}$ phosphodiesterase," American Journal of Physiology-Cell Physiology, vol. 296, no. 6, pp. C1428-C1439, 2009.

[7] E. K. Jackson, “The $2^{\prime}, 3^{\prime}$-cAMp-adenosine pathway," American Journal of Physiology-Renal Physiology, vol. 301, no. 6, pp. F1160-F1167, 2011.

[8] T. Diamantstein and A. Ulmer, "The antagonistic action of cyclic GMP and cyclic AMP on proliferation of B and T lymphocytes," Immunology, vol. 28, no. 1, pp. 113-119, 1975.

[9] E. Boadu, S. Vaskinn, E. Sundkvist, R. Jaeger, and G. Sager, "Inhibition by guanosine cyclic monophosphate (cGMP) analogues of uptake of $\left[{ }^{3} \mathrm{H}\right] 3^{\prime}, 5^{\prime}$-cGMP without stimulation of ATPase activity in human erythrocyte inside-out vesicles," Biochemical Pharmacology, vol. 62, no. 4, pp. 425-429, 2001.

[10] E. K. Jackson, "Discovery and roles of $2^{\prime}, 3^{\prime}$-cAMP in biological systems," in Handbook of Experimental Pharmacology, pp. 1-24, 2016.

[11] T. Van Damme, D. Blancquaert, P. Couturon, D. Van Der Straeten, P. Sandra, and F. Lynen, "Wounding stress causes rapid increase in concentration of the naturally occurring $2^{\prime}, 3^{\prime}$ isomers of cyclic guanosine- and cyclic adenosine monophosphate (cGMP and cAMP) in plant tissues," Phytochemistry, vol. 103, pp. 59-66, 2014.

[12] A. L. Okorokov, K. I. Panov, W. A. Offen et al., "RNA cleavage without hydrolysis. Splitting the catalytic activities of binase with Asn101 and Thr101 mutations," Protein Engineering, vol. 10, no. 3, pp. 273-278, 1997.

[13] J. V. Sokurenko, P. V. Zelenikhin, V. V. Ulyanova, A. I. Kolpakov, D. Muler, and O. N. Ilinskaya, "Identification of $2^{\prime}, 3^{\prime}$-cGMP as an intermediate of RNA catalytic cleavage by binase and evaluation of its biological action," Bioorganicheskaia Khimiia, vol. 41, no. 1, pp. 37-43, 2015.

[14] K. Takahashi and S. Moore, “The enzymes," in Nucleic Acids, Part B, vol. 15, pp. 435-467, Academic Press, New York, NY, USA, 1982.

[15] E. Dudkina, A. Kayumov, V. Ulyanova, and O. Ilinskaya, "New insight into secreted ribonuclease structure: binase is a natural dimer," PLoS ONE, vol. 9, no. 12, Article ID el15818, 2014.

[16] M. Peana, S. Medici, V. M. Nurchi, G. Crisponi, J. I. Lachowicz, and M. A. Zoroddu, "Manganese and cobalt binding in a multihistidinic fragment," Dalton Transactions, vol. 42, no. 46, pp. 16293-16301, 2013.

[17] D. E. Draper, "A guide to ions and RNA structure," RNA, vol. 10, no. 3, pp. 335-343, 2004.

[18] J.-L. Leroy, M. Guéron, G. Thomas, and A. Favre, "Role of divalent ions in folding of tRNA," European Journal of Biochemistry, vol. 74, no. 3, pp. 567-574, 1977.

[19] J. S. Summers, J. Shimko, F. L. Freedman, C. T. Badger, and M. Sturgess, "Displacement of $\mathrm{Mn}^{2+}$ from RNA by $\mathrm{K}^{+}, \mathrm{Mg}^{2+}$, neomycin $\mathrm{B}$, and an arginine-rich peptide: indirect detection of nucleic acid/ligand interactions using phosphorus relaxation enhancement," Journal of the American Chemical Society, vol. 124, no. 50, pp. 14934-14939, 2002.

[20] D. E. Draper, D. Grilley, and A. M. Soto, "Ions and RNA folding," Annual Review of Biophysics and Biomolecular Structure, vol. 34, pp. 221-243, 2005.
[21] L.-Q. Sun, M. J. Cairns, E. G. Saravolac, A. Baker, and W. L. Gerlach, "Catalytic nucleic acids: from lab to applications," Pharmacological Reviews, vol. 52, no. 3, pp. 325-347, 2000.

[22] S. A. Woodson, "Metal ions and RNA folding: a highly charged topic with a dynamic future," Current Opinion in Chemical Biology, vol. 9, no. 2, pp. 104-109, 2005.

[23] A. M. Saunders and V. J. DeRose, "Beyond $\mathrm{Mg}^{2+}$ : functional interactions between RNA and transition metals," Current Opinion in Chemical Biology, vol. 31, pp. 153-159, 2016.

[24] A.-S. Sjögren, E. Pettersson, B.-M. Sjöberg, and R. Strömberg, "Metal ion interaction with cosubstrate in self-splicing of group I introns," Nucleic Acids Research, vol. 25, no. 3, pp. 648-653, 1997.

[25] Y. Shi, G. Zhao, and W. Kong, "Genetic analysis of riboswitchmediated transcriptional regulation responding to $\mathrm{Mn}^{2+}$ in Salmonella," The Journal of Biological Chemistry, vol. 289, no. 16, pp. 11353-11366, 2014.

[26] T.-C. Kuo, O. W. Odom, and D. L. Herrin, "Unusual metal specificity and structure of the group I ribozyme from Chlamydomonas reinhardtii 23S rRNA," FEBS Journal, vol. 273, no. 12, pp. 2631-2644, 2006.

[27] T. Pan, D. M. Long, and O. C. Uhlenbeck, "Divalent metal ions in RNA folding and catalysis," in The RNA World, R. F. Gesteland and J. F. Atkins, Eds., pp. 271-302, Cold Spring Harbor Laboratory Press, New York, NY, USA, 1993.

[28] A. L. Feig and O. C. Uhlenbeck, "The role of metal ions in RNA biochemistry," in The RNA World, 2nd Ed.: The Nature of Modern RNA Suggests a Prebiotic RNA World? R. F. Gesteland, T. R. Cech, and J. Atkins, Eds., pp. 287-319, Cold Spring Harbor Laboratory Press, New York, NY, USA, 1999.

[29] L. R. Stefan, R. Zhang, A. G. Levitan, D. K. Hendrix, S. E. Brenner, and S. R. Holbrook, "MeRNA: a database of metal ion binding sites in RNA structures," Nucleic Acids Research, vol. 34, pp. D131-D134, 2006.

[30] E. Freisinger and R. K. O. Sigel, "From nucleotides to ribozymes-a comparison of their metal ion binding properties," Coordination Chemistry Reviews, vol. 251, no. 13-14, pp. 1834-1851, 2007.

[31] L. Rulíšek and J. Šponer, "Outer-shell and inner-shell coordination of phosphate group to hydrated metal ions $\mathrm{Mgg}^{2+}, \mathrm{Cu}^{2+}$, $\left.\mathrm{Zn}^{2+}, \mathrm{Cd}^{2+}\right)$ in the presence and absence of nucleobase. The role of nonelectrostatic effects," The Journal of Physical Chemistry B, vol. 107, no. 8, pp. 1913-1923, 2003.

[32] A. A. Makarov, A. Kolchinsky, and O. N. Ilinskaya, "Binase and other microbial RNases as potential anticancer agents," BioEssays, vol. 30, no. 8, pp. 781-790, 2008.

[33] H. A. Cabrera-Fuentes, P. V. Zelenikhin, A. I. Kolpakov, K. Preissner, and O. N. Ilinskaya, "Comparative toxicity of binase towards tumor and normal cell," Toxicon, pp. 104-105, 2012.

[34] V. A. Mitkevich, I. Y. Petrushanko, P. V. Spirin et al., "Sensitivity of acute myeloid leukemia Kasumi-1 cells to binase toxic action depends on the expression of KIT and AML1-ETO oncogenes," Cell Cycle, vol. 10, no. 23, pp. 4090-4097, 2011.

[35] V. A. Mitkevich, O. N. Ilinskaya, and A. A. Makarov, "Antitumor RNases: killer's secrets," Cell Cycle, vol. 14, no. 7, pp. 931-932, 2015.

[36] O. N. Ilinskaya, I. Singh, E. Dudkina, V. Ulyanova, A. Kayumov, and G. Barreto, "Direct inhibition of oncogenic KRAS by Bacillus pumilus ribonuclease (binase)," Biochimica et Biophysica Acta (BBA)_Molecular Cell Research, vol. 1863, no. 7, pp. 1559$1567,2016$. 
[37] R. S. Mahmud and O. N. Ilinskaya, "Antiviral activity of binase against the pandemic influenza A (H1N1) virus," Acta Naturae, vol. 5, no. 19, pp. 44-51, 2013.

[38] O. N. Ilinskaya and R. Shah Mahmud, "Ribonucleases as antiviral agents," Molecular Biology, vol. 48, no. 5, pp. 615-623, 2014. 

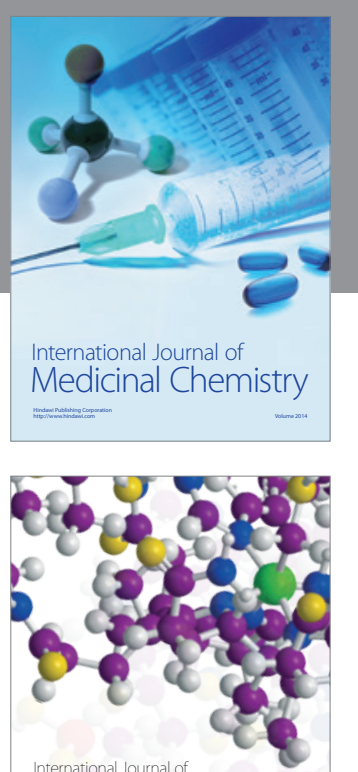

Carbohydrate Chemistry

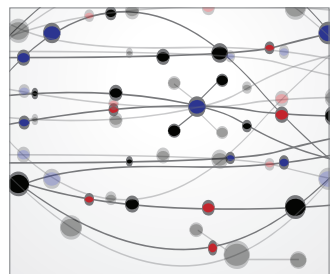

The Scientific World Journal
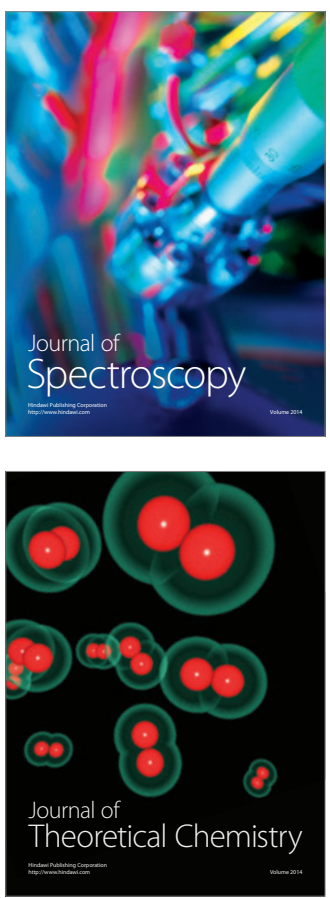
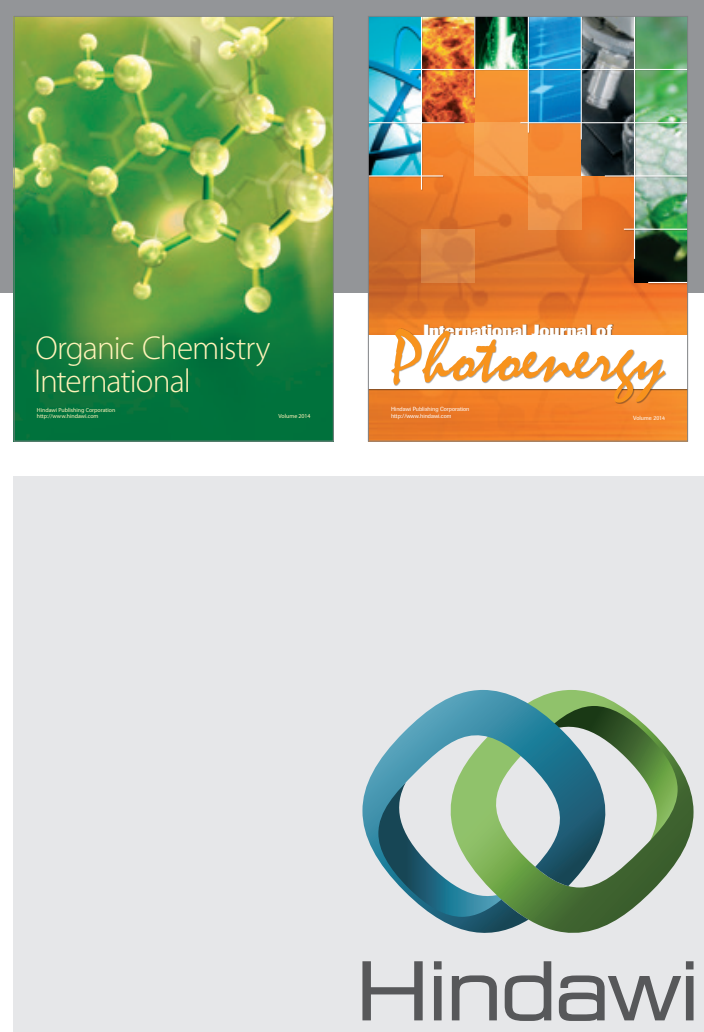

Submit your manuscripts at

http://www.hindawi.com

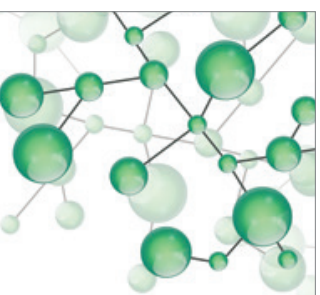

International Journal of

Inorganic Chemistry

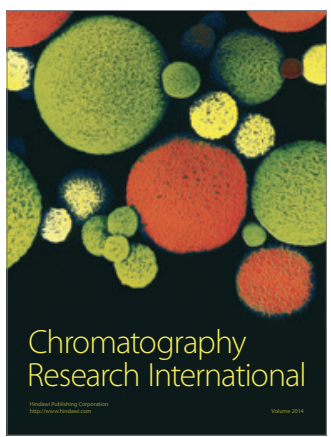

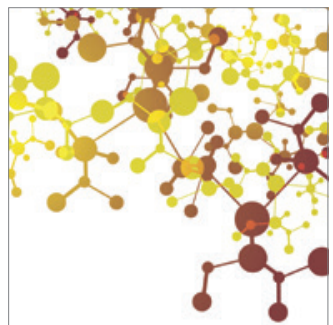

Applied Chemistry
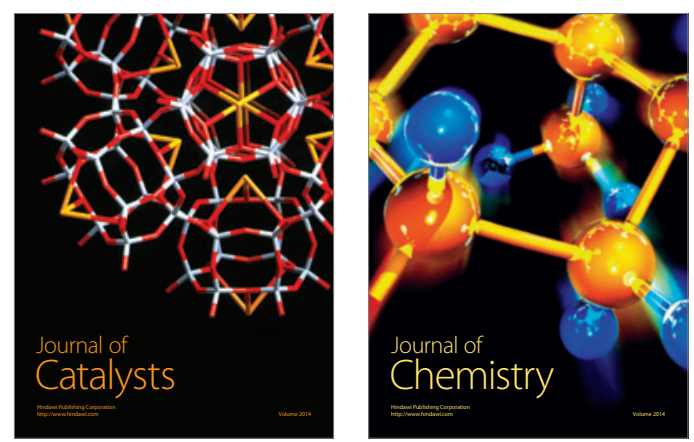
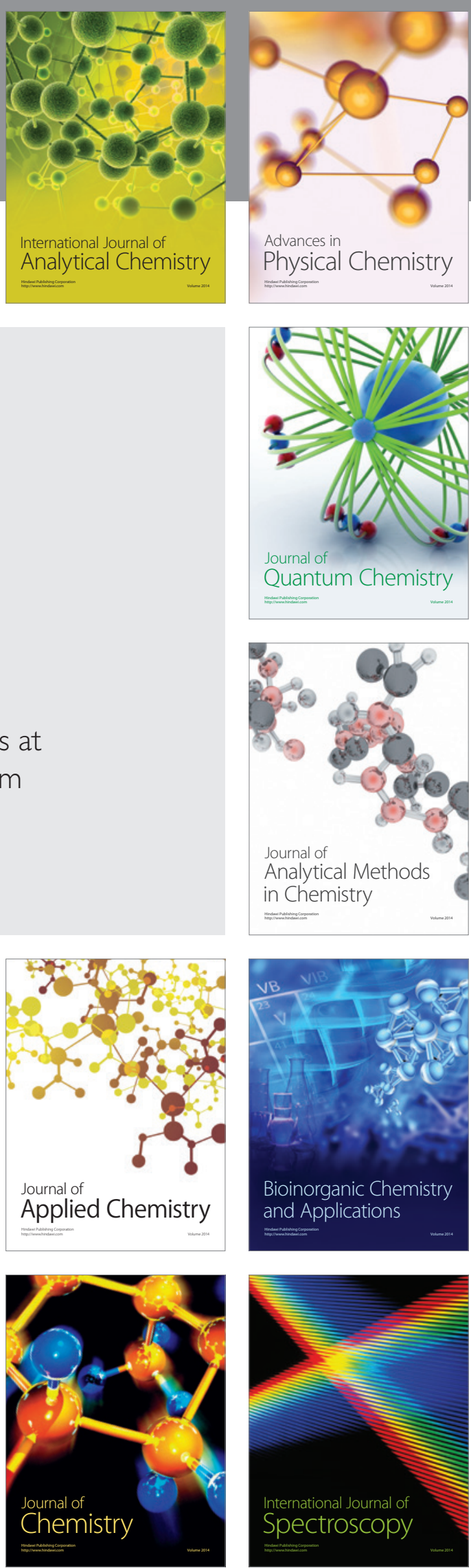